\title{
Methyl Eugenol, 1,8-Cineole and Nerolidol Rich Essential Oils with their Biological Activities from three Melaleuca Species Growing in Tarai Region of North India
}

\section{Archana Joshi ${ }^{1}$}

https://orcid.org/0000-0001-7299-1761

Om Prakash ${ }^{1^{*}}$

https://orcid.org/0000-0002-2767-6997

\section{Anil Kumar Pant ${ }^{1}$}

https://orcid.org/0000-0003-0358-6150

\author{
Ravendra Kumar ${ }^{1}$ \\ https://orcid.org/0000-0002-0296-5231 \\ Lech Szczepaniak ${ }^{2}$ \\ https://orcid.org/0000-0002-2209-7830
}

\section{Kamila Kucharska-Ambrożej²}

https://orcid.org/0000-0002-7150-7111

${ }^{1}$ G.B. Pant University of Agriculture and Technology, College of Basic Science and Humanities, Department of Chemistry, Pantnagar, Uttarakhand, India; '2University of Bialystok, Department of Environmental Chemistry, Ciolkowskiego 1K, 15-245 Bialystok, Poland.

Editor-in-Chief: Alexandre Rasi Aoki

Associate Editor: Jane Manfron Budel

Received: 2021.03.26; Accepted: 2021.06.10.

${ }^{*}$ Correspondence: oporgchem@gmail.com (O.P.).

HIGHLIGHTS

- E-nerolidol, 1,8-cineol and methyl eugenol rich species of Melaleuca were identified in this study.

- Essential oils exhibited strong antioxidant,antibacterial and Invitro anti inflammatory activity.

- These marker constitutents impart valuable place of this crop in agriculture.

Abstract: The essential oils from the fresh leaves of three Melalecua spp. viz; Melaleuca leucadendron (L.) Melaleuca linariifolia Sm. and Melaleuca bracteata F. Muell. growing in Tarai region of North India were analyzed by a combination of gas chromatography/mass spectrometry. The analysis revealed the presence of several constituents of industrial and pharmacological importance. M. leucadendron essential oil was found to be dominated by E-nerolidol (85.7\%) rich chemotype. 1,8-cineole $(61.1 \%)$ along with significant presence of $\alpha$-terpineol (12.3\%), $\alpha$-pinene $(4.0 \%), \beta$-myrcene $(3.8 \%)$, and $E$-caryophyllene (1.7\%) were identified in the essential oil from $M$. linariifolia Similarly $M$. bracteata was dominated by the presence of phenylpropanoids viz; methyl eugenol (74.8\%) and methyl cinnamate (8.0\%). The essential oils were studied for their in-vitro antioxidant, anti-inflammatory and antimicrobial potential. All the oils revealed potential antioxidant activity with maximum in $M$. bracteata essential oil. All the oils exhibited significant antibacterial activity against Bacillus megaterium, Staphylococcus aureus, Escherichia coli,Salmonella typhimurium and anti-fungal activity against phytopathogenic fungi Fusarium oxysporum, Sclerotinia sclerotiorum, Exserohilum turcicum and Curvularia lunata. The observations from present study suggest further cultivation of Melaleucas and its commercialization as industrial crops. 
Keywords: Methyl eugenol; 1,8-cineole; (E)-nerolidol; Melaleuca Antioxidant; Antifungal; antimicrobial.

\section{INTRODUCTION}

The genus Melaleuca is an aromatic and medicinal shrub. The shrubs are generally found in open forest, woodland or shrubland, particularly along water courses and the edges of swamps [1]. The Melaleuca genus belongs to the Melaleucae tribe, subfamily Myrtiodeae [2] and predominantly occurs in Australia. It comprises approximately 230 species of worldwide occurrence with 220 species endemic to Australia and Tasmania, but also occurring in Indonesia and New Papua Guinea [3,4]. The family Myrtaceae is well known for economically important timber trees, especially Eucalyptus spp., oils (e.g., Eucalyptus spp., Melaleuca spp.), and cultivated as ornamentals plants such as Callistemon (bottlebrush), Chamelaucium (wax-flower), Eucalyptus spp., Leptospermum (tea tree), and Myrtus (myrtle) [5]. The fleshy-fruited species include many economically important food plants, agricultural crops, and ornamentals, including the Mediterranean genus Myrtus (myrtle), spices such as clove (Syzygium aromaticum /L./ Merr. \& L.M. Perry), allspice (Pimenta dioica /L./ Merr.), and bay rum (Pimenta racemosa / Mill./ J. W. Moore), and the fruits of Psidium (guavas), Myrciaria, Eugenia, Syzygium, Plinia and Luma[6]. The plants of genus Melaleuca are commonly known as tea tree and are rich source of commercially valuable volatile oils [7]. The essential oils of various Melaleuca species have been reported to show extensive compositional variability under different geographic and ecological conditions. Phenylpropanoids (methyl eugenol, $(E)$-methylisoeugenol), monoterpenoids (mainly, 1,8-cineole, terpinen-4-ol, terpinolene, along with p-cymene, $\alpha$-terpinene, $\alpha$-terpineol, $\alpha$-pinene), and sesquiterpenoids $((E)$-nerolidol, viridiflorol, ledol, $\beta$-caryophyllene) have been reported as marker constituents in the essential oils from most of the Melaleuca species[8-15]. Commercially useful essential oils have been sourced from the broad leaved M.quinquenervia (niaouli oil) and $M$. cajuputi (cajuput oil) and the small-leaved M. alternifolia-M. linariifolia complex[16]. These oil have been used mainly in the manufacture of cosmetics, germicides and as antiseptic agents. Studies also revealed the broad spectrum antimicrobial potential of essential oils $[17,18]$. The leaves and stem of several Melaleuca species are source of essential oils with strong aroma for medicinal application, with potential use for cancer treatment alongwith its use in traditional medicine against many pathological conditions like acne, wounds, sores, dandruff, and skin lesions [19-21]. Previous studies also suggest the allelopathic properties of Melaleuca species resulting in an inhibition of other species in the same ecosystem. The bare ground in Melaleuca forests was an excellent example of allelopathy in this genus [22].

Literature survey revealed no pre-existing comparative study of Melaleuca species from different climatic zones of India. In present scenario people are again relying on natural resources for pharmaceutical and neutraceutical practices. Hence its need of time to screen these indigenous essential oil resources for their judicious exploitation, cultivation and commercialization. The present study was carried out to investigate the compositional diversity among the essential oils of three Melaleuca species viz; Melaleuca bracteata, Melaleuca linariifolia and Melaleuca leucadendron grown in Tarai region of North India. The bioactivity of these oils as antifungal, antimicrobial, and antioxidant agents was also assessed to evaluate their pharmaceutical and neutraceutical values.

\section{MATERIAL AND METHODS}

\section{Plant materials and isolation of essential oil}

The fresh aerial parts of Melaleuca species were collected from Medicinal Plant Research and Development Centre (MRDC) of the G.B.Pant University, Pantnagar. (M.bracteata and M.linariifolia) and Forest Training Institute, Lalkuan (M.leucadendra) (Nainital, Uttarakhand). Voucher specimen and herbarium record of the plant have been retained in Herbarium. Freshly collected leaves were hydrodistilled separately in a Clevenger apparatus for 3-4 $\mathrm{h}$ for extraction of essential oils. The essential oils were collected, dehydrated over anhydrous $\mathrm{Na}_{2} \mathrm{SO}_{4}$ and stored in an amber color vials at $4{ }^{\circ} \mathrm{C}$ in refrigerator for further analysis.

\section{Analysis and identification of essential oil constituents}

The GC/MS analysis was carried out using Agilent 6890 gas chromatograph fitted with Mass Selective Detector 5973 and Autosampler 7683. Column HP-5 (30 m× $0.25 \mathrm{~mm}$ I.D.; $0.25 \mu \mathrm{m}$ of film thickness) was used. The injector temperature was $250^{\circ} \mathrm{C}$. Helium was used as carrier gas with a flow rate of $1.0 \mathrm{~mL} / \mathrm{min}$. 
Detector temperature was $150{ }^{\circ} \mathrm{C}$, source temperature was $230{ }^{\circ} \mathrm{C}$, ionization energy was $70 \mathrm{eV}$. Chromatograms were recorded in a programmed regime of linear temperature which increase from $50{ }^{\circ} \mathrm{C}$ to $320{ }^{\circ} \mathrm{C}$ at the rate of $3{ }^{\circ} \mathrm{C} / \mathrm{min}$. Compounds of the essential oil and relative percentage composition are compiled. Linear retention indices $(\mathrm{RI})$ were calculated using a homologous series of $n$-alkanes $\left(\mathrm{C}_{8}-\mathrm{C}_{25}\right)$ under the same temperature-programmed conditions. The compounds were identified with the help of NIST 14 and Wiley 9 mass spectra libraries and by comparing the experimental RI with those from literature [23].

\section{Antioxidant activity}

\section{DPPH Radical scavenging activity}

2,2-diphenylpicrylhydrazil (DPPH) free radical scavenging activity was performed by following the reported protocols with modifications [24,25]. Briefly the reaction mixture contained $5 \mathrm{~mL}$ of $0.004 \%$ methanol solution of DPPH and different amount ( $5-25 \mu \mathrm{g} / \mathrm{mL}$ ) of essential oils. The solutions were rapidly mixed and scavenging capacity was measured spectrophotometrically(Thermo Scientific Evolution 201) by monitoring the decrease in absorbance at $517 \mathrm{~nm}$. BHT was used as positive control while reaction mixture (DPPH radical solution) minus essential oil solution was taken as control. Inhibition of free radicals (IC \%) was calculated by using the formula:

$$
I C \%=A_{0}-A_{s} / A_{0} \times 100
$$

Where, $A_{0}=$ Absorbance value of Control sample $A_{s}=$ Absorbance value of Test sample IC = Inhibitory concentration. Percent inhibition was plotted against concentration and the standard curve was drawn using standard antioxidant $(\mathrm{BHT})$ to calculate the $\mathrm{IC}_{50}$ values for standard and essential oils.

\section{Metal chelating activity}

The metal chelating activity of essential oils were examined by the reported methods [26]. It was based on the principle of the $\mathrm{Fe}^{+2}$ chelating ability where the absorbance of the $\mathrm{Fe}^{+2}$ - ferrozine complex was measured at $562 \mathrm{~nm} .0 .1 \mathrm{~mL}$ of $2 \mathrm{mM} \mathrm{FeCl}_{2} .4 \mathrm{H}_{2} \mathrm{O}, 0.2 \mathrm{~mL}$ of $5 \mathrm{mM}$ ferrozine and $4.7 \mathrm{~mL}$ of methanol was added to different amounts ( $5-25 \mu \mathrm{g} / \mathrm{mL}$ ) of essential oils. After incubation, the absorbance of test samples were measured at $562 \mathrm{~nm}$. The IC\% was calculated as:

$$
I C \%=A_{0}-A_{s} / A_{0} \times 100
$$

Where, $A_{0}=$ Absorbance value of Control sample $A_{s}=$ Absorbance value of Test sample IC = Inhibitory concentration. Percent inhibition was plotted against concentration and the standard curve was drawn using standard antioxidant (citric acid) to calculate the $\mathrm{IC}_{50}$ values for standard and essential oils.

\section{Reducing power}

The reducing power of essential oils were analyzed by the method developed earlier and recently being used [27]. In brief varying amount $(5-25 \mu \mathrm{g} / \mathrm{mL})$ of essential oils were mixed with $2.5 \mathrm{~mL}$ of phosphate buffer ( $200 \mathrm{mM}, \mathrm{pH}=6.6)$ and $2.5 \mathrm{~mL}$ of $1 \%$ potassium ferricyanide, $\mathrm{K}_{3}\left[\mathrm{Fe}(\mathrm{CN})_{6}\right]$. After 20 minute incubation at $50 \pm 1^{\circ} \mathrm{C}, 2.5 \mathrm{~mL}$ of trichloroacetic acid was added to the mixtures, followed by centrifugation at $650 \mathrm{RPM}$ for $10 \mathrm{~min}$. The upper layer $(1.0 \mathrm{~mL})$ was mixed with $5.0 \mathrm{~mL}$ of distilled water and $1 \mathrm{~mL}$ of $0.1 \%$ ferric chloride. The resultant solutions were measured at $700 \mathrm{~nm}$ using UV spectrophotometer. All the readings were taken in triplicate and BHT was used as the standard.

The reducing power of samples was calculated using the formula given below:

$$
\text { Reducing activity } \%=A_{0}-A_{s} / A_{0} \times 100 \text {. }
$$

Where, $A_{0}=$ Absorbance value of Control sample $A_{s}=$ Absorbance value of test sample.Percent inhibition was plotted against concentrations and the standard curve was drawn using standard antioxidant (BHT) to calculate the $\mathrm{RP}_{50}$ values for standard and essential oils.

\section{Nitric oxide scavenging activity}

Sodium nitroprusside (SNP) was used to generate nitric oxide and was measured by the Griess reagent. It is based on the principle that SNP in aqueous solution at physiological pH spontaneously generates NO, which interacts with oxygen to produce nitrite ions that can be estimated by the use of Griess reagent. Scavengers of NO compete with oxygen leading to reduced production of NO. $2 \mathrm{ml}$ of SNP 
(10 mM) in phosphate buffer saline (PBS) $\mathrm{pH} 7.4$ was mixed with different amount $(5-25 \mu \mathrm{g} / \mathrm{mL})$ of essential oil and incubated at $25^{\circ} \mathrm{C}$ for two and half hours. The above were reacted with $1 \mathrm{~mL}$ of Griess reagent ( $1 \%$ sulphanilamide, $0.1 \%$ naphthylethylenediamine dichloride and $2 \mathrm{~mL}$ orthophosphoric acid). Finally absorbance was measured at 546nm. Ascorbic acid was taken as standard [28].

\section{Super oxide radical scavenging activity}

$1 \mathrm{~mL}$ of nitroblue terazolium (156 mM), $1.0 \mathrm{~mL}$ nicotinamide adenine dinucleotide (reduced) (468 mM) and $0.1 \mathrm{~mL}$ of phenazine methosulphate solution (PMS) in $0.1 \mathrm{M}$ of phosphate buffer solution (pH 7.4) were added to different amounts (5- $25 \mu \mathrm{g} / \mathrm{mL}$ ), of essential oils followed by incubation at $25{ }^{\circ} \mathrm{C}$ for $5 \mathrm{~min}$ and the absorbance was read at $560 \mathrm{~nm}$ against blank, containing all reagent except PMS. Ascorbic acid was taken as standard [29].

Super oxide radical scavenging activity was calculated by following equation.

$$
\text { Superoxide radical scavenged }(\%)=I C \%=A_{0}-A_{s} / A_{0} \times 100 \text {. }
$$

Where, $A_{0}=$ Absorbance value of Control sample $A=$ Absorbance value of Test sample IC = Inhibitory concentration. Percent inhibition was plotted against concentration. The standard curve was drawn using standard antioxidant (ascorbic acid) to calculate the $\mathrm{IC}_{50}$ values for standard and essential oil.

\section{Antifungal activity}

\section{Plant pathogenic fungi}

The soil borne pathogenic fungi Fusarium oxysporum, Sclerotinia sclerotiorum, Curvularia lunata and Exserohilum turcicum were procured from the Department of Plant Pathology, College of Agriculture, G.B.P.U.A\&T, Pantnagar, India. Cultures of each fungal species were maintained on Potato Dextrose Agar (PDA) and stored at $4^{\circ} \mathrm{C}$.

\section{In-vitro antifungal activity}

Antifungal activity of the oils was tested by the poisoned food technique using potato dextrose agar (PDA) medium against the test fungi. The essential oil samples were prepared by dissolving the requisite amounts in $10 \%$ DMSO and then added into $20 \mathrm{~mL}$ PDA to obtain different final concentrations [30,31]. Mycelial plugs $(2.0 \mathrm{~mm}$ in diameter) from the edges of each culture were incubated in the center of each PDA plate (85 mm diameter). The control sets were prepared using equal amounts of $10 \%$ DMSO in place of the oil. The prepared plates were inoculated aseptically with assay discs of the test fungi and incubated at $26 \pm 2{ }^{\circ} \mathrm{C}$ for 3-7 days until the growth in the control plates reached the edge of the plates. Growth inhibition of each fungal strain was calculated as the percentage inhibition of radial growth relative to the control. The plates were used in triplicate for each treatment [32]. IC $\mathrm{C}_{50}$ values of constituents were graphically obtained from the dose response curves based on measurement at five different concentrations.

\section{Antibacterial activity}

\section{Bacterial strain}

Four bacterial strains of significant importance were used to test the antibacterial properties of the essential oils. The antimicrobial activity was tested against two Gram positive bacteria Bacillus megaterium and Staphylococcus aureus and two Gram negative Escherichia coli and Salmonella typhimurium. These strains were obtained from the Department of Veterinary Public Health, College of Veterinary, G.B.P.U.A.T, Pantnagar, India. All the strains were stored in the appropriate medium before use. The antibacterial activity was studied using standard protocol [33].

\section{Determination of the minimum inhibitory concentration (MIC)}

The MIC was determined using standard protocol with the serial dilution of $5 \mu \mathrm{g} / \mathrm{mL}, 10 \mu \mathrm{g} / \mathrm{mL}, 15 \mu \mathrm{g} / \mathrm{mL}$, $20 \mu \mathrm{g} / \mathrm{mL}, 25 \mu \mathrm{g} / \mathrm{mL}$. A $100 \mu \mathrm{L}$ suspension containing $1 \times 10^{6} \mathrm{CFU} / \mathrm{mL}$ of bacteria were spread on nutrient agar plates [34]. The wells were filled with $50 \mu \mathrm{L}$ of essential oil solution in the inoculated nutrient agar plates. The bacterial plates were incubated at $37 \pm 2^{\circ} \mathrm{C}$ for 24 hours. The MIC was defined as the minimum 
concentration of the oil inhibiting the visible growth of each bacterium on the agar plate, so the lowest concentration of each essential oil showing a clear zone of inhibition was taken as the MIC. DMSO was used as the negative control, while refamycin was used as positive control. Each experiment was performed in triplicate.

\section{Determination of in-vitro anti-inflammatory activity}

\section{Inhibition of albumin denaturation}

In vitro anti-inflammatory activity was performed by the method generally being practiced [35]. The reaction mixture $(5.0 \mathrm{~mL})$ consisted of $0.2 \mathrm{~mL}$ of egg albumin (hen's fresh egg), $2.8 \mathrm{~mL}$ of phosphate buffered saline (PBS, pH 6.4) and $2 \mathrm{~mL}$ of varying amounts (250-1000 ppm) of essential oils. Similar volume of double-distilled water was used as control. The mixtures were incubated at $\left(37 \pm 2{ }^{\circ} \mathrm{C}\right)$ in an incubator for $15 \mathrm{~min}$ followed by heating at $70^{\circ} \mathrm{C}$ for $5 \mathrm{~min}$. After cooling, the absorbance was measured at $660 \mathrm{~nm}$ by using distilled water as blank. Diclofenac sodium was used as reference drug and treated similarly for determination of absorbance. The percentage inhibition of protein denaturation was calculated by using the following formula:

$$
\% \text { inhibition }=100 \times(\mathrm{Vt} / \mathrm{Vc}-1)
$$

Where, $\mathrm{V}_{\mathrm{t}}=$ absorbance of test sample, $\mathrm{V}_{\mathrm{c}}=$ absorbance of control. The oil concentration for $50 \%$ inhibition $\left(\mathrm{IC}_{50}\right)$ was determined by plotting percentage inhibition with respect to control against treatment concentration.

\section{Statistical analysis}

The mean values and standard deviations were calculated for all tests. The data were analyzed using SPSS 16.0 statistical software. The results were calculated by Analysis of Variance (ANOVA). The means were compared by Duncan tests at a level of significance of $p<0.05$.

\section{RESULTS}

\section{Chemical constituents of essential oils}

The chemical composition of essential oils led to the presence of marker constituents previously recorded from Melaleuca species with slight qualitative and quantitative differences. GC-MS analysis of the essential oils led to the identification of over 90 constituents from three species. The oil yield for M.leucadendron was highest $(1.02 \%)$ followed by M.bracteata $(0.62 \%)$ and M.linariifolia $(0.60 \%)$. The detailed composition has been presented in Table 1. 
Table 1. Comparative Chemical compositions of Melaleuca species

\begin{tabular}{|c|c|c|c|c|c|c|c|c|}
\hline \multirow{3}{*}{ S.N. } & \multirow{3}{*}{ Compounds } & \multirow{3}{*}{ RI } & \multicolumn{6}{|c|}{ \% Composition } \\
\hline & & & \multicolumn{3}{|c|}{ Present Study } & \multicolumn{3}{|c|}{ Padalia et.al $[36,37,49]$} \\
\hline & & & $\begin{array}{c}M . \\
\text { leucadendron }\end{array}$ & $\begin{array}{c}M . \\
\text { linariifola }\end{array}$ & $\begin{array}{c}M . \\
\text { bracteata }\end{array}$ & $\begin{array}{c}M . \\
\text { leucadendron } \\
(2015)\end{array}$ & $\begin{array}{c}M . \\
\text { linariifola } \\
(2015)\end{array}$ & $\begin{array}{c}M . \\
\text { bracteata } \\
(2017)\end{array}$ \\
\hline 1. & $\begin{array}{l}\text { Methyl 2- } \\
\text { methylbutanoate }\end{array}$ & 780 & 0.1 & 0.1 & $\mathrm{t}$ & - & 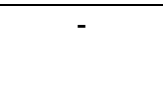 & - \\
\hline 2. & $\alpha$-thujene & 924 & - & 0.1 & 0.1 & - & $t$ & 0.08 \\
\hline 3. & a-pinene & 932 & 0.4 & 4.0 & 0.1 & $\mathrm{t}$ & 1.99 & - \\
\hline 4. & camphene & 948 & $\mathrm{t}$ & 0.1 & - & 0.10 & $\mathrm{t}$ & - \\
\hline 5. & benzaldehyde & 960 & 1.2 & - & $t$ & - & - & - \\
\hline 6. & sabinene & 969 & & & & 0.64 & & \\
\hline 7. & $\beta$-pinene & 975 & $\mathrm{t}$ & 1.6 & 0.1 & 0.50 & 0.85 & 0.04 \\
\hline 8. & $\begin{array}{l}\text { 6-methyl-5-hepten-2- } \\
\text { one }\end{array}$ & 985 & 0.1 & - & - & - & & - \\
\hline 9. & $\beta$-myrcene & 990 & $\mathrm{t}$ & 3.8 & 0.3 & 0.10 & 1.78 & 0.12 \\
\hline 10. & pseudolimonene & 1002 & - & 0.2 & - & - & - & - \\
\hline 11. & $\alpha$-phellandrene & 1002 & - & - & 1.0 & - & - & 0.16 \\
\hline 12. & p-mentha -1(7),8-diene & 1002 & & & & & 0.14 & \\
\hline 13. & a-terpinene & 1014 & - & 0.3 & 0.1 & - & - & - \\
\hline 14. & p-cymene & 1021 & - & - & 0.7 & - & 0.21 & 0.36 \\
\hline 15. & limonene & 1025 & 0.4 & - & 0.3 & - & 0.15 & 0.30 \\
\hline 16. & 1,8-cineole & 1030 & 0.1 & 61.1 & 0.2 & 0.30 & 77.40 & 0.34 \\
\hline 17. & E-ocimene & 1046 & $\mathrm{t}$ & 0.1 & 0.1 & & - & - \\
\hline 18. & $y$-terpinene & 1056 & $\mathrm{t}$ & 0.8 & 0.1 & $\mathrm{t}$ & 0.41 & - \\
\hline 19. & a-terpinolene & 1086 & 0.1 & 0.2 & 1.1 & - & - & 0.26 \\
\hline 20. & Methyl benzoate & 1093 & $\mathrm{t}$ & 0.1 & $\mathrm{t}$ & - & - & - \\
\hline 21. & linalool & 1099 & 0.7 & 0.2 & 1.2 & 0.52 & 0.19 & 0.94 \\
\hline 22. & exo-fenchol & 1120 & & & & & 0.10 & \\
\hline 23. & camphor & 1141 & & & & 0.38 & & \\
\hline 24. & isopulegol & 1142 & 0.4 & - & $\mathrm{t}$ & - & - & - \\
\hline 25. & citronellal & 1152 & - & - & 0.1 & - & - & - \\
\hline 26. & $\delta$-terpineol & 1165 & - & 0.6 & - & - & 0.46 & - \\
\hline 27. & Terpin-4-ol & 1174 & $t$ & 1.1 & 0.2 & $\mathrm{t}$ & 0.76 & 0.40 \\
\hline 28. & p-cymen-8-ol & 1183 & - & - & 0.1 & - & - & - \\
\hline 29. & $\alpha$-terpineol & 1190 & 0.1 & 12.3 & 0.8 & 0.10 & 7.72 & 0.54 \\
\hline 30. & Methyl chavicol & 1197 & - & - & 0.4 & - & - & 0.32 \\
\hline 31. & citronellol & 1228 & 0.2 & - & 0.4 & - & - & 0.04 \\
\hline 32. & neral & 1239 & - & - & 0.1 & 0.22 & - & - \\
\hline 33. & E-geraniol & 1253 & $\mathrm{t}$ & - & 0.1 & - & - & 0.07 \\
\hline 34. & linalyl acetate & 1254 & & & & - & & \\
\hline 35. & Methyl citronellate & 1260 & - & - & 0.1 & - & - & - \\
\hline 36. & $\alpha$-citral & 1269 & - & - & 0.2 & - & - & - \\
\hline 37. & geranial & 1270 & & & & & & 0.12 \\
\hline 38. & bornyl acetate & 1284 & & & & 0.11 & & \\
\hline 39. & S-methyl thiobenzoate & 1290 & 0.1 & - & - & - & - & - \\
\hline 40. & Z-methyl cinnamate & 1304 & - & - & 0.1 & - & - & - \\
\hline 41. & Methyl geranate & 1323 & - & - & 0.1 & - & - & - \\
\hline 42. & $\delta$-elemene & 1335 & & & & - & & \\
\hline 43. & $\alpha$-terpinyl acetate & 1346 & & & & 0.53 & & \\
\hline 44. & $\alpha$-cubebene & 1348 & - & - & 0.1 & - & - & - \\
\hline 45. & Citronellyl acetate & 1353 & - & - & 0.2 & - & - & - \\
\hline 46. & eugenol & 1356 & 0.1 & 0.3 & 0.5 & - & $\mathrm{t}$ & 0.04 \\
\hline 47. & Neryl acetate & 1364 & - & 0.1 & - & - & $\mathrm{t}$ & - \\
\hline 48. & $\alpha$-ylangene & 1369 & & & & & $\mathrm{t}$ & \\
\hline 49. & isoledene & 1371 & - & 0.1 & & - & & - \\
\hline
\end{tabular}




\begin{tabular}{|c|c|c|c|c|c|c|c|c|}
\hline 50. & $\alpha$-copaene & 1374 & - & - & 0.1 & - & $\mathrm{t}$ & - \\
\hline 51. & E-methyl cinnamate & 1383 & - & - & 8.0 & - & - & 4.12 \\
\hline 52. & Geranyl acetate & 1383 & - & 0.1 & - & - & $\mathrm{t}$ & - \\
\hline 53. & $\beta$-bourbonene & 1387 & & & & - & & \\
\hline 54. & $\alpha$-gurjunene & 1408 & - & 0.1 & - & - & - & - \\
\hline 55. & Methyl eugenol & 1416 & - & 0.6 & 74.8 & - & $t$ & 88.18 \\
\hline 56. & E- $\beta$-caryophyllene & 1417 & 0.9 & 1.7 & - & 1.52 & 2.88 & - \\
\hline 57. & Z- $\beta$-copaene & 1431 & - & - & 0.5 & - & - & - \\
\hline 58. & $\alpha$-guaiene & 1432 & & & & & 0.46 & \\
\hline 59. & aromadendrene & 1438 & - & 0.4 & 0.2 & - & $t$ & - \\
\hline 60. & Selina-5,11-diene & 1441 & - & 0.1 & - & - & - & - \\
\hline 61. & a-humulene & 1452 & 0.2 & 0.3 & 0.2 & 0.22 & 0.31 & - \\
\hline 62. & E-Muurola-3,5-diene & 1453 & - & - & 0.1 & - & - & - \\
\hline 63. & $\gamma$-gurjunene & 1470 & - & 0.1 & - & - & $t$ & - \\
\hline 64. & Cabreuva oxide D & 1475 & 0.1 & - & - & - & - & - \\
\hline 65. & E-cadina-1(6),4-diene & 1475 & - & - & 0.1 & - & - & - \\
\hline 66. & D-germacrene & 1480 & - & - & 1.1 & - & - & 0.60 \\
\hline 67. & $\beta$-selinene & 1484 & - & 0.1 & - & - & - & - \\
\hline 68. & $\alpha$-amorphene & 1485 & & & & & 0.10 & \\
\hline 69. & $\delta$-selinene & 1489 & - & 0.1 & - & - & - & - \\
\hline 70. & viridiflorene & 1493 & - & 0.5 & - & - & - & - \\
\hline 71. & bicyclogermacrene & 1496 & - & - & 0.4 & - & - & - \\
\hline 72. & E-methyl isoeugenol & 1497 & & & & & & 0.20 \\
\hline 73. & $\alpha$-muurolene & 1499 & - & 0.1 & 0.1 & - & 0.18 & - \\
\hline 74. & $\beta$-cadinene & 1506 & - & 0.6 & - & - & - & - \\
\hline 75. & $\mathrm{E}, \mathrm{E}-\alpha$-farnesene & 1508 & 0.1 & - & - & - & - & - \\
\hline 76. & $\mathrm{y}$-cadinene & 1513 & - & 0.1 & 0.1 & 0.10 & 0.12 & - \\
\hline 77. & $\beta$-curcumene & 1515 & & & & & 0.43 & . \\
\hline 78. & E-calamenene & 1522 & - & 0.2 & - & - & 0.10 & - \\
\hline 79. & $\delta$-cadinene & 1522 & & & & - & & . \\
\hline 80. & Z-calamenene & 1524 & - & - & 0.7 & - & - & - \\
\hline 81. & Z-nerolidol & 1531 & & & & 0.10 & & \\
\hline 82. & Cadina-1,4-diene & 1532 & - & - & 0.2 & - & - & - \\
\hline 83. & $\alpha$-calacorene & 1542 & - & 1.1 & $\mathrm{t}$ & - & - & - \\
\hline 84. & ledol & 1557 & - & 0.2 & - & - & - & - \\
\hline 85. & elemicin & 1558 & - & - & 0.2 & - & - & 0.30 \\
\hline 86. & germacrene-B & 1558 & & & & & 0.99 & \\
\hline 87. & palustrol & 1565 & - & 0.2 & 0.1 & - & - & - \\
\hline 88. & E-nerolidol & 1568 & 85.7 & - & - & 90.85 & 0.10 & - \\
\hline 89. & spathulenol & 1575 & - & 0.2 & 0.3 & - & $\mathrm{t}$ & 0.22 \\
\hline 90. & Caryophyllene oxide & 1581 & 3.7 & - & - & 0.99 & 0.10 & 0.14 \\
\hline 91. & globulol & 1582 & - & 1.2 & 0.3 & 0.70 & - & - \\
\hline 92. & viridiflorol & 1591 & 0.6 & 0.3 & 0.1 & 0.19 & - & - \\
\hline 93. & Cubeban-11-ol & 1592 & - & 0.5 & 0.1 & - & 0.52 & - \\
\hline 94. & fokienol & 1599 & 0.4 & - & - & - & - & - \\
\hline 95. & juneperol & 1599 & & & & & $t$ & \\
\hline 96. & rosifoliol & 1600 & - & 0.4 & 0.1 & - & $\mathrm{t}$ & - \\
\hline 97. & Humulene epoxide II & 1608 & 0.3 & - & $\mathrm{t}$ & - & & - \\
\hline 98. & 1,10-di-epi-cubenol & 1612 & - & 1.3 & $\mathrm{t}$ & - & 0.10 & - \\
\hline 99. & 10-epi-y-eudesmol & 1622 & & & & 0.14 & & \\
\hline 100 & epicubenol & 1626 & - & $\mathrm{t}$ & 0.1 & - & 0.25 & - \\
\hline 101 & $\begin{array}{l}\text { Allo-aromadendrene } \\
\text { epoxide }\end{array}$ & 1632 & 0.1 & - & - & - & - & - \\
\hline 102 & isospathulenol & 1636 & - & 0.2 & - & - & - & - \\
\hline 103 & $\begin{array}{l}\text { Caryophylla- } \\
4(12), 8(13) \text {-diene-5-a-ol }\end{array}$ & 1636 & 0.5 & - & - & - & - & - \\
\hline 104 & T-cadinol & 1638 & - & 0.2 & - & - & - & - \\
\hline 105 & epi-a-cadinol & 1638 & & & & 0.20 & $\mathrm{t}$ & \\
\hline 106 & T-muurolol & 1640 & - & - & 0.5 & - & - & - \\
\hline
\end{tabular}




\begin{tabular}{|c|c|c|c|c|c|c|c|c|}
\hline 107 & a-muurolol & 1643 & & & & & & 0.20 \\
\hline 108 & ס-cadinol & 1644 & - & 0.1 & 0.1 & - & - & - \\
\hline 109 & $\beta$-eudesmol & 1649 & & & & $\mathrm{t}$ & & \\
\hline 110 & $\alpha$-cadinol & 1653 & - & 0.1 & 0.4 & 0.33 & - & 0.14 \\
\hline 111 & $\begin{array}{l}\text { E-14-hydroxy-9-epi } \\
\text { caryophyllene }\end{array}$ & 1670 & 0.1 & - & $\mathrm{t}$ & - & - & - \\
\hline 112 & cadalane & 1672 & - & 0.1 & - & & $\mathrm{t}$ & - \\
\hline 113 & $\beta$-bisabolol & 1675 & & & & $\mathrm{t}$ & & . \\
\hline 114 & (Z)-nerolidyl acetate & 1679 & & & & $t$ & & \\
\hline 115 & a-bisabolol & 1685 & 0.2 & - & - & & - & - \\
\hline 116 & 2Z,6Z-farnesol & 1698 & 0.1 & - & - & & - & - \\
\hline 117 & 2Z,6E-farnesol & 1721 & 0.7 & 0.3 & - & & - & - \\
\hline 118 & Iso-longifolol & 1732 & 0.1 & - & - & & - & - \\
\hline 119 & methylconiferylaldehyde & 1777 & - & - & 0.3 & & - & - \\
\hline 120 & phytol & 2112 & - & 0.3 & - & & - & - \\
\hline 121 & Total identified & & 97.8 & 99.0 & 98.1 & 98.84 & 98.90 & 98.24 \\
\hline 122. & $\begin{array}{l}\text { Monoterpene } \\
\text { hydrocarbons }\end{array}$ & & 0.9 & 11.2 & 4.0 & 1.34 & 5.53 & 1.30 \\
\hline 123. & $\begin{array}{l}\text { Oxygenated } \\
\text { monoterpenes }\end{array}$ & & 1.6 & 75.6 & 12.4 & 2.16 & 86.63 & 2.42 \\
\hline 124 & $\begin{array}{l}\text { Sesquiterpene } \\
\text { hydrocarbons }\end{array}$ & & 1.2 & 5.7 & 3.9 & 1.84 & 5.67 & 0.60 \\
\hline 125 & $\begin{array}{l}\text { Oxygenated } \\
\text { sesquiterpenes }\end{array}$ & & 92.2 & 5.3 & 2.1 & 93.50 & 1.07 & 0.70 \\
\hline 126. & Others & & 1.9 & 0.6 & 75.7 & - & - & 93.14 \\
\hline
\end{tabular}

Mode of identification: RI (retention index), MS, $\mathrm{t}=$ trace $(<0.1 \%)$

The most abundant component of essential oil of M.leucadendron was E-nerolidol (85.7\%). Other major components identified were caryophyllene oxide (3.7\%), benzaldehyde (1.2\%), 2Z,6E-farnesol $(0.7 \%)$, viridifloral $(0.6 \%)$ and caryophyllene $(0.9 \%)$ etc. The major constituents identified in M.linarifolia essential oil were 1,8-cineole (61.1\%) along with significant presence of $\alpha$-terpineol $(12.3 \%)$, $\alpha$-pinene $(4.0 \%), \beta$-myrcene (3.8\%), E-caryophyllene (1.7\%), a-calacorene (1.1\%), globulol (1.2\%), 1,10-di-epicubenol $(1.3 \%)$, $\beta$-pinene $(1.6 \%)$ while eugenol methyl ether $(74.8 \%)$ was identified as a principal component in M.bracteata essential oil along with methyl cinnamate (7.97\%). The RI and percentage contribution are shown in Table 1. The essential oils from M.bracteata and M. lineriifolia showed quantitative variability in chemical composition when compared with the earlier reports [36,37]. The chemical composition of essential oil of Melaleuca leucadendron was mostly composed of oxygenated sesquiterpenes (92.2\%), whereas Melaleuca linariifolia essential oil consisted of oxygenated monoterpenes (75.6\%). The Melaleuca bracteata essential oil was characterized by dominance of phenylpropanoid methyl eugenol $(74.8 \%)$.

The compounds a-phellandrene (1.0\%), p-cymene (0.7\%), methyl chavicol $(0.4 \%), \alpha$-citral $(0.2 \%)$, methylcinnamate $(8.0 \%)$, $\beta$-copane $(0.5 \%)$, D-germacrene $(1.1 \%)$, bicyclogermacrene $(0.4 \%)$, calamenene $(0.7 \%)$, cadina-1,4-diene $(0.2 \%)$, elimicin $(0.2 \%)$, T- muurolol $(0.5 \%)$, methyl coniferylaldehyde $(0.3 \%)$ were found in $M$. bracteata essential oil but were missing in $M$. leucadendron and $M$. lineriifolia essential oils, whereas caryophyllene oxide (3.7\%), fokienol (0.4\%), caryophylla-4(12),8(13)-dien-5-alphaol (0.5\%), epi- $\alpha$ bisabolol $(0.1 \%)$, $\alpha$-bisabolol $(0.2 \%), 2 Z, 6 Z$-farnesol $(0.1 \%)$, iso-longifolol $(0.1 \%)$, the minor constituents of $M$. leucadendron were absent in the other two essential oils. Similarly, psuedolimonene $(0.2 \%)$, $\delta$-terpineol $(0.6 \%)$, viridiflorene $(0.5 \%), \beta$-cadinene $(0.6 \%)$, E-calamene $(0.2 \%)$, ledol $(0.2 \%)$, isospathulenol $(0.2 \%)$, Tcadinol $(0.2 \%)$, phytol $(0.3 \%)$ were identified in M.lineriifolia essential oil but were absent in M.leucadendron and M.bracteata essential oils. Previously 1,8-cineole has been reported as the major component in the essential oil of $M$. leucadendron grown in Cuba, Ivory Coast, India, Indonesia[7,38,39]. Another report from Thiland revealed terpinolene (29.21\%), $\alpha$-terpinene $(22.55 \%), 2$-carene $(8.53 \%)$ and $\alpha$ phellandrene $(7.61 \%)$ as the major compounds of $M$. leucadendron essential oil. Recently Siddique and coauthors,reported eugenol methyl ether (95.4\%) as the dominant component of $M$. leucadendron essential oil [40]. Our findings corroborate the earlier report, where E-nerolidol (90.85\%) was the major component although the quantity of $E$-nerolidol $(85.7 \%)$ was smaller than reported in previous findings[41]. Caryophyllene oxide (3.7\%) in the present study is higher in amount than that of earliar report[41]. 
Our results of $M$. linariifolia essential oil characterized it as a rich source of monoterpenoides such as 1,8 -cineole and $\alpha$-terpineol, $\alpha$-pinene, $\beta$-pinene, $\beta$-myrcene. As per earlier reports, the essential oil composition of $M$. linariifolia from Australia was characterized as 'terpinen-4-ol' and '1,8-cineole' type based upon the dominance of these monoterpenoids[16,42-44]. However, the volatile oil of M.linariifolia from Brazil was shown to be characterized with a high content of methyleugenol (86.8\%) [13]. Our results show similarity with the results published by Padalia and coauthors, $2015 \mathrm{a}$ where 1,8 -cineole $(77.40 \%)$ and $\alpha$ terpineol $(7.72 \%)$ were the major components with some differences in quantitative makeup [36]. Aboutabl and coauthors investigated the essential oils from three Melaleuca species growing in Egypt and reported that eugenol is the major component of $M$. bracteata (97.7\%)[8]. Pino and coauthors isolated the leaf essential oil of $M$. leucadendron from Cuba and identified it as a Virdifloral type chemotype with major presence of viridiflorol (28.2\%) and 1,8-cineole (21.3\%) [45].In another report, Pino and coauthors analyzed the phytochemical composition and antioxidant activity of leaf and fruit essential oil of $M$. leucadendron from Cuba[46]. A total of fourty one and sixty four compounds were identified and the major portion of leaf and fruit essential oil was composed of 1,8-cineole (43.0\%) and virdifloral $(47.6 \%)$. The other major compounds detected were viridiflorol (24.2\%), $\alpha$-terpineol $(7.0 \%)$, $\alpha$-pinene $(5.3 \%)$, and limonene $(4.8 \%)$ in the leaf oil, whereas the fruit essential oil consisted of globulol (5.8\%), guaiol (5.3\%), and a-pinene $(4.5 \%)[46]$.

The composition report of the essential oil of M.bracteata was in agreement with the previous reports where methyl eugenol was the major component of the leaf essential oil $[8,47,48]$.Based on the quantity of nerolidol, 1,8-cineole and methyl eugenol in present study it can be concluded that these shrubs can be good natural source of these neutaceutically important terpenoids by developing the agricultural practices to cultivate these species in wastelands which can be also a good source of revenue generation for local residents.

\section{Antioxidant activity}

\section{DPPH Radical scavenging activity}

All the essential oils showd scavenging activity in a dose dependent manner (Table 2). In this study, the antioxidant activity of essential oils were compared with BHT, a reference standard antioxidant compound. It was found that the essential oils of Melaleuca species exhibited good antioxidant activity. The essential oil from $M$. bracteata was found most effective antioxidant $\left(\mathrm{IC}_{50}=4.06 \pm 0.02 \mu \mathrm{g} / \mathrm{mL}\right)$ followed by M.linariifolia $\left(\mathrm{IC}_{50}=10.96 \pm 0.00 \mu \mathrm{g} / \mathrm{mL}\right)$ compared to $\mathrm{BHT}\left(\mathrm{IC}_{50}=9.29 \pm 0.09 \mu \mathrm{g} / \mathrm{mL}\right)$, whereas M.leucadendron essential oil revealed moderate potential $\left(\mathrm{IC}_{50}=16.24 \pm 0.05 \mu \mathrm{g} / \mathrm{mL}\right)$ towards radical scavenging activity(Table2).

\section{Metal chelating activity}

All the essential oils exhibited dose dependent metal chelating activity. Melaleuca leucadendron and Melaleuca linariifolia essential oils showed remarkable metal chelating activity with $\mathrm{IC}_{50}$ of $9.56 \pm 0.31$ $\mu \mathrm{g} / \mathrm{mL}$ and $10.51 \pm 0.39 \mu \mathrm{g} / \mathrm{mL}$ compared to positive control citric acid $\left(\mathrm{IC}_{50}=4.04 \pm 0.63 \mu \mathrm{g} / \mathrm{mL}\right)$ while Melaleuca bracteata essential oil with $\mathrm{IC}_{50}$ of $8.80 \pm 0.44 \mu \mathrm{g} / \mathrm{mL}$ exhibited highest chelating activity among all the tested oils(Table2).

\section{Reducing power}

The Melaleuca bracteata essential oil was found most effective in reduction of $\mathrm{Fe}^{+3}\left(\mathrm{IC}_{50}=2.11 \pm 0.39\right.$ $\mu \mathrm{g} / \mathrm{mL})$ depicting comparable potential with standard reducing agent $\mathrm{BHT}\left(\mathrm{IC}_{50}=2.46 \pm 0.25 \mu \mathrm{g} / \mathrm{mL}\right)$. The Melaleuca linariifolia essential oil demonstrated significant reducing capability $\left(\mathrm{IC}_{50}=4.18 \pm 0.33 \mu \mathrm{g} / \mathrm{mL}\right)$ whereas moderate activity was observed in M.leucadendron essential oil (Table2).

\section{Super oxide radical scavenging activity}

M.leucadendron $\left(\mathrm{IC}_{50}=20.92 \pm 0.31 \mu \mathrm{g} / \mathrm{mL}\right)$ and M.bracteata $\left(\mathrm{IC}_{50}=21.79 \pm 0.85 \mu \mathrm{g} / \mathrm{mL}\right)$ essential oils demonstrated significant superoxide radical scavenging activity compared to standard ascorbic acid $\left(\mathrm{IC}_{50}=\right.$ $9.85 \pm 0.16 \mu \mathrm{g} / \mathrm{mL}$ ) as indicated by their $\mathrm{IC}_{50}$ values. A moderate radical scavenging activity was observed for M.linariifolia essential oil ( $\left.\mathrm{IC}_{50}=25.83 \pm 0.19 \mu \mathrm{g} / \mathrm{mL}\right)$. 


\section{Nitric oxide(NO) radical scavenging activity}

All the tested essential oils exhibited strong nitric oxide (NO) radical scavenging activity. Remarkably strong nitric oxide radical scavenging potential was observed in Melaleuca bracteata essential oil $\left(\mathrm{IC}_{50}=\right.$ $11.59 \pm 0.09 \mu \mathrm{g} / \mathrm{mL})$ compared to ascorbic acid $\left(\mathrm{IC}_{50}=10.36 \pm 0.45 \mu \mathrm{g} / \mathrm{mL}\right)$. M. linariifolia $\left(\mathrm{IC}_{50}=12.68 \pm\right.$ $0.09 \mu \mathrm{g} / \mathrm{mL})$ and $M$. Leucadendron were the least active among the three tested essential oils $\left(\mathrm{IC}_{50}=16.17\right.$ $\pm 0.06 \mu \mathrm{g} / \mathrm{mL}$ ). All the tested oils demonstrated radical scavenging activity in a dose dependent manner with maximum scavenging at highest concentration (Table 2).

Table 2. Antioxidant activity $\left(\mathrm{IC}_{50}\right)$ of essential oils of Melaleuca Species.

\begin{tabular}{|l|l|l|l|l|c|}
\hline \multirow{2}{*}{$\begin{array}{c}\text { Essential } \\
\text { oil/Standard }\end{array}$} & \multicolumn{5}{c|}{ Antioxidant activity(IC50) } \\
\cline { 2 - 6 } & $\begin{array}{c}\text { DPPH radical } \\
\text { Scavenging }\end{array}$ & Metal chelating & Reducing power & $\begin{array}{l}\text { NO Radical } \\
\text { scavenging }\end{array}$ & $\begin{array}{c}\text { SO Radical } \\
\text { Scavenging }\end{array}$ \\
\hline M.leucadendron & $16.24 \pm 0.05$ & $9.56 \pm 0.31$ & $12.89 \pm 1.72$ & $16.17 \pm 0.06$ & $20.92 \pm 0.31$ \\
\hline M.linerifolia & $10.946 \pm 0.00$ & $10.51 \pm 0.39$ & $4.18 \pm 0.33$ & $12.68 \pm 0.09$ & $25.83 \pm 0.19$ \\
\hline M.bracteata & $4.06 \pm 0.02$ & $8.80 \pm 0.44$ & $2.11 \pm 0.39$ & $11.60 \pm 0.09$ & $21.79 \pm 0.85$ \\
\hline Citric acid $^{*}$ & - & $4.04 \pm 0.63$ & - & - & - \\
\hline BHT $^{*}$ & $9.29 \pm 0.09$ & - & $2.46 \pm 0.25$ & - & - \\
\hline Ascorbic Acid & - & - & - & $10.36 \pm 0.45$ & $9.85 \pm 0.16$ \\
\hline
\end{tabular}

Values are mean \pm S.D., ${ }^{\star}$ Standard antioxidant

\section{Antifungal activity}

The essential oils exhibited moderate to good antifungal potential by inhibiting the mycelial growth of pathogenic fungi. The inhibitory effect of the oil varied from $7.08 \%$ to $90 \%$ (Table 3). At the concentration of $500 \mathrm{ppm}$, the oils showed highest inhibitory effect on the radial growth of S. sclerotiorum. S. sclerotiorum and E.turcicum were found to be the most inhibited fungal pathogens by the oils. Essential oil of $M$. bracteata exhibited a strong antifungal effect against all the tested phytopathogens (up to $90 \%$ ) as compared to other oils.

Table 3. Antifungal activity of essential oils of Melaleuca Species

\begin{tabular}{|c|c|c|c|c|c|}
\hline \multirow[t]{2}{*}{ Essential oil } & \multirow{2}{*}{$\begin{array}{l}\text { Conc. } \\
\text { (ppm) }\end{array}$} & \multicolumn{4}{|c|}{ Mycelial growth inhibition (\%) } \\
\hline & & $\begin{array}{l}\text { Fusarium } \\
\text { oxysporum }\end{array}$ & $\begin{array}{l}\text { Sclerotinia } \\
\text { sclerotiorum }\end{array}$ & Curvularia Iunata & $\begin{array}{l}\text { Exserohilum } \\
\text { turcicum }\end{array}$ \\
\hline \multirow{5}{*}{ M.leucadendron } & 500 & $18.95 \pm 1.301^{\mathrm{a}}$ & $80.83 \pm 1.30^{\mathrm{a}}$ & $39.66 \pm 3.53^{a}$ & $56.66 \pm 1.11^{a}$ \\
\hline & 250 & $12.91 \pm 0.72^{b}$ & $77.70 \pm 0.95^{\mathrm{ab}}$ & $38.75 \pm 2.5^{a}$ & $55.18 \pm 0.64^{\mathrm{ab}}$ \\
\hline & 100 & $12.08 \pm 1.90^{\mathrm{bc}}$ & $75.83 \pm 3.20^{b}$ & $35.41 \pm 2.00^{\mathrm{ab}}$ & $54.81 \pm 0.64^{b}$ \\
\hline & 50 & $11.33 \pm 1.01^{\mathrm{bc}}$ & $75.16 \pm 0.314^{b}$ & $32.91 \pm 3.14^{\mathrm{b}}$ & $52.59 \pm 1.28^{c}$ \\
\hline & 25 & $10 \pm 1.25^{c}$ & $71.66 \pm 1.44^{c}$ & $32.91 \pm 1.57^{b}$ & $51.11 \pm 0.96^{c}$ \\
\hline $\mathrm{IC}_{50}(\mathrm{ppm})$ & & 2332.65 & 1465.22 & 1136.35 & 318.57 \\
\hline \multirow{5}{*}{ M.linariifolia } & 500 & $28.95 \pm 2.00^{\mathrm{a}}$ & $58.58 \pm 0.88^{a}$ & $38.16 \pm 0.57^{a}$ & $59.07 \pm 1.15^{a}$ \\
\hline & 250 & $20.37 \pm 1.51^{b}$ & $51.87 \pm 1.08^{b}$ & $35.62 \pm 1.65^{\mathrm{a}}$ & $55.55 \pm 1.11^{b}$ \\
\hline & 100 & $9.79 \pm 1.57^{c}$ & $50.87 \pm 3.68^{b}$ & $31.25 \pm 1.25^{\mathrm{b}}$ & $54.62 \pm 3.61^{\mathrm{bc}}$ \\
\hline & 50 & $9.16 \pm 1.57^{c}$ & $25 \pm 1.25^{\mathrm{c}}$ & $27.91 \pm 3.14^{\mathrm{b}}$ & $54.44 \pm 2.22^{\mathrm{bc}}$ \\
\hline & 25 & $7.70 \pm 0.368^{c}$ & $7.08 \pm 1.44^{\mathrm{d}}$ & $23.54 \pm 3.55^{c}$ & $52.40 \pm 2.50^{c}$ \\
\hline IC 50 (ppm) & & 938.50 & 318.81 & 883.13 & 253.02 \\
\hline \multirow{5}{*}{ M.bracteata } & 500 & $46.87 \pm 1.65^{\mathrm{a}}$ & $82.91 \pm 0.36^{a}$ & $75.20 \pm 0.36^{a}$ & $90 \pm 1.11^{a}$ \\
\hline & 250 & $36.12 \pm 1.59^{b}$ & $76.04 \pm 0.95^{b}$ & $60.20 \pm 0.954^{b}$ & $88.51 \pm 0.64^{a}$ \\
\hline & 100 & $31.87 \pm 2.86^{c}$ & $63.87 \pm 0.45^{c}$ & $32.29 \pm 2.81^{\mathrm{c}}$ & $65.18 \pm 0.64^{b}$ \\
\hline & 50 & $17.29 \pm 1.57^{d}$ & $47.08 \pm 2.00^{d}$ & $31.08 \pm 1.44^{\mathrm{c}}$ & $58.14 \pm 1.69^{c}$ \\
\hline & 25 & $7.29 \pm 0.95^{\mathrm{e}}$ & $27.70 \pm 0.36^{e}$ & $20.12 \pm 0.66^{d}$ & $54.62 \pm 3.61^{c}$ \\
\hline$I_{50}(\mathrm{ppm})$ & 25 & 498.11 & 85.88 & 239.97 & 89.70 \\
\hline Carbendazim & & $100.00 \pm 0.00$ & $100.00 \pm 0.00$ & $100.00 \pm 0.00$ & $100.00 \pm 0.00$ \\
\hline
\end{tabular}

Values are Mean \pm S.D. , Within a column means followed by the same letter are not significantly different $(P>0.05)$. Means followed by a different letter are significantly different $(P<0.005)$. 


\section{Antibacterial activity}

The zone of inhibition around the well diameters and minimum inhibitory concentrations (MICs) of the essential oils against the microorganisms tested are shown in Table 4. The results obtained from the agar well diffusion method for the essential oils revealed $S$. typhimurium to be the most sensitive microorganism with the largest inhibition zones $(20.67,20.67$ and $23.67 \mathrm{~mm}$ against $M$. leucadendron, $M$. linariifolia and $M$. bracteata essential oils respectively), while the minimum zone of inhibition were exhibited by S.aureus $(16.33,14.00,15.67 \mathrm{~mm})$ against M.leucadendron, M.linariifolia and M.bracteata essential oils respectively.

Table 4. Antibacterial potential of essential oils of Melaleuca Species

\begin{tabular}{|c|c|c|c|c|c|}
\hline \multirow[t]{2}{*}{ S.N. } & \multirow[t]{2}{*}{ Sample } & \multicolumn{4}{|c|}{ Zone of inhibition $(\mathrm{mm})$} \\
\hline & & B.megaterium & S.typhimurium & E.coli & S.aureus \\
\hline \multirow{6}{*}{1.} & M.leucadendron & & & & \\
\hline & 10 & $11.33 \pm 0.58^{c}$ & $12.67 \pm 0.58^{d}$ & $16.33 \pm 1.15^{b}$ & $10.33 \pm 1.52^{\mathrm{c}}$ \\
\hline & 15 & $13.33 \pm 0.58^{b}$ & $14.33 \pm 0.58^{\mathrm{c}}$ & $17 \pm 0.00^{b}$ & $13.67 \pm 0.58^{b}$ \\
\hline & 20 & $14.33 \pm 0.58^{b}$ & $16.33 \pm 0.58^{b}$ & $18.33 \pm 0.58^{a}$ & $15.67 \pm 0.58^{a}$ \\
\hline & 25 & $18.33 \pm 0.58^{a}$ & $20.67 \pm 0.58^{a}$ & $19.00 \pm 0.00^{a}$ & $16.33 \pm 1.15^{\mathrm{a}}$ \\
\hline & $\operatorname{MIC}(\mu \mathrm{g} / \mathrm{mL})$ & 10 & 10 & 5 & 10 \\
\hline \multirow{6}{*}{2.} & M.linariifolia & & & & \\
\hline & 10 & $10.33 \pm 0.58^{c}$ & $11.67 \pm 0.58^{c}$ & $13.33 \pm 0.58^{c}$ & $8.67 \pm 1.15^{d}$ \\
\hline & 15 & $12.67 \pm 0.58^{b}$ & $15.33 \pm 0.58^{b}$ & $14.67 \pm 0.58^{b}$ & $10.33 \pm 0.58^{c}$ \\
\hline & 20 & $13.67 \pm 0.58^{b}$ & $16.33 \pm 0.58^{b}$ & $16 \pm 1.00^{a}$ & $12.33 \pm 0.58^{b}$ \\
\hline & 25 & $19.67 \pm 0.58^{a}$ & $20.67 \pm 1.15^{a}$ & $17 \pm 0.00^{\mathrm{a}}$ & $14 \pm 0.00^{\mathrm{a}}$ \\
\hline & $\operatorname{MIC}(\mu \mathrm{g} / \mathrm{mL})$ & 10 & 10 & 5 & 10 \\
\hline \multirow{6}{*}{3.} & M.bracteata & & & & \\
\hline & 10 & $11 \pm 0.00^{c}$ & $16.67 \pm 0.58^{c}$ & $13.33 \pm 0.58^{d}$ & $10.67 \pm 1.15^{c}$ \\
\hline & 15 & $11.67 \pm 0.58^{c}$ & $17.67 \pm 0.58^{\mathrm{c}}$ & $15.67 \pm 0.58^{c}$ & $12.67 \pm 1.15^{b}$ \\
\hline & 20 & $13.33 \pm 0.58^{b}$ & $20.67 \pm 0.70^{\mathrm{b}}$ & $18.67 \pm 1.15^{b}$ & $13.67 \pm 1.15^{b}$ \\
\hline & 25 & $14.67 \pm 0.58^{\mathrm{a}}$ & $23.67 \pm 0.58^{a}$ & $20.67 \pm 0.58^{a}$ & $15.67 \pm 0.58^{\mathrm{a}}$ \\
\hline & $\operatorname{MIC}(\mu \mathrm{g} / \mathrm{mL})$ & 10 & 5 & 5 & 10 \\
\hline \multirow{2}{*}{4.} & Refamycin & & & & \\
\hline & $25 \mu \mathrm{g} / \mathrm{mL}$ & $31.33 \pm 1.22^{a}$ & $35 \pm 1.00^{a}$ & $32.67 \pm 1.15^{a}$ & $27 \pm 1.00^{a}$ \\
\hline
\end{tabular}

Values are Mean \pm S.D. Within a column means followed by the same letter are not significantly different $(P>0.05)$. Means

followed by a different letter are significantly different $(P<0.005)$.

\section{In-vitro anti-inflammatory activity}

As part of the investigation on the mechanism of the anti-inflammatory activity, ability of essential oils to inhibit protein denaturation was studied. All the tested oils were found effective in inhibiting heat induced albumin denaturation (Table 5). The $\mathrm{IC}_{50}$ for $M$. leucadendron essential oil was $27.82 \pm 0.24 \mu \mathrm{g} / \mathrm{mL}$ whereas that of $M$. linariifolia was $23.43 \pm 0.25 \mu \mathrm{g} / \mathrm{mL}$. Melaleuca bracteata essential oil was found most effective in inhibiting protein denaturation with $\mathrm{IC}_{50}$ of $20.68 \pm 0.004 \mu \mathrm{g} / \mathrm{mL}$ compared to the standard diclofenac sodium $\left(\mathrm{IC}_{50}=11.93 \pm 0.03 \mu \mathrm{g} / \mathrm{mL}\right)$.

Table 5. Anti-inflammatory activity of essential oils of Melaleuca Species

\begin{tabular}{|l|c|c|c|c|}
\hline \multirow{2}{*}{$\begin{array}{l}\text { Anti inflammatory } \\
\text { activity }\end{array}$} & \multicolumn{4}{|c|}{ Essential oil/Standard } \\
\hline IC $_{50}$ Value & $27.82 \pm 0.242$ & $23.43 \pm 0.247$ & $20.68 \pm 0.004$ & $11.93 \pm 0.033$ \\
\hline
\end{tabular}

\section{DISCUSSION}

This study was undertaken to compare the essential oil composition, antioxidant and biological activity of the three Melaleuca species: Melaleuca leucadendron, Melaleuca linariifolia and Melaleuca bracteata from Northern plains of India. Differences and similarities in the groups of terpenes were established between the three Melaleuca species based on the present studies. The major findings from the three 
species were $(E)$-nerolidol, 1,8-cineole and methyl eugenol. M.bracteata exhibited highest antioxidant activity followed by M.linariifolia and M.leucadendron essential oil. Oils exhibited significant antibacterial activity. The microorganisms selected in our studies are mostly human pathogens whose effects are noticeable in skin, intestinal and respiratory infections. The essential oils revealed remarkable antimicrobial potential against all the tested organisms. This observation is particularly noteworthy because essential oils are known to be more active against gram-positive than gram-negative bacteria but in our study essential oils exhibited noticeable activity against all the bacterial species tested [50]. All the oils showed moderate to strong anti-inflammatory potential within the tested range of concentrations. The results also revealed differential ability of oils in inhibiting the phytopathogenic fungal growth.

$(E)$-nerolidol a sesquiterpene alcohol with pleasant odour have several reported biological and pharmacological activities such as antimalarial, antileishmanial, antiulcer, antibacterial, antifungal, and as a topical skin penetration enhancer whereas 1,8-cineole is extensively used in food-flavor, pharmaceutical, and cosmetic industries [51-54]. Several pharmacological activities including anti-microbial, anticancer, anti-inflammatory, antioxidant, bactericidal, herbicidal, insecticidal have been reported for 1,8-cineole $[13,55,56]$. In addition 1, 8-cineole possess strong larvicidal, insecticidal, fumigant, repellent and antifeedent and anti-inflammatory activities [43, 56-58]. Methyl eugenol has been reported to possess antiepileptic and anti-inflammatory activity $[59,60]$. Eugenol was found to inhibit the growth of various multi drug resistant pathogenic bacteria such as E. coli, Staphylococcus, Proteus, Klebsiella, Enterobacter, $H$. pylori and Pseudomonas isolated from human subjects [61, 62]. Thus various reports supports our claim that the antioxidant, antimicrobial and antinflammatory activity of essential oils could be due to their major components such as 1.8-cineole, methyl eugnol, E-nerolidol. Nevertheless, the presence of minor component could also play a role in the biological activity.

\section{CONCLUSION}

The increasing population pressure and constraint of agriculture lands due to several developmental activities in India have raised alarm for food security and naturally the essential oil crops may limit their cultivation. Melaleuca species can grow in wild and are perennial species which have less agriculture cost inputs for their commercial production and can be grown in wastelands and used for filling of damp areas. The high content of (E)-nerolidol in the essential oil of $M$. leucadendron suggests this species as a new potential source of (E)-nerolidol which have a widespread use in the food-flavor, perfumery, cosmetics and pharmaceutical industries. The oil yield , 1,8-cineole content, and the biological activity of essential oil from $M$. linariifolia favours the cultivation and promising use of this species for isolation of 1,8-cineole and in pharmaceutical industry. Another species Melaleuca bracteata was found as a rich source of methyl eugenol, the commercially important molecule. All the oils showed significant in-vitro antifungal and antibacterial activity against tested fungal phytopathogens and bacterial strains responsible for plant diseases and several chronic conditions. The anti-inflammatory potential gives additional remarks to these species. Conclusively the outcomes of chemical composition and various activities suggested the cultivation and development of these species as commercial crops in agro forestry systems.

Funding: This research received no external funding.

Acknowledgments: We thankfully acknowledge Dept. of Veterinary Public Health (VPH) for providing experimental facilities and Department of Biological Sciences, G.B., Pant University of Agriculture and Technology, Pantnagar for taxonomic identification and providing voucher specimen

Conflicts of Interest: The authors declare no conflict of interest.

\section{REFERENCES}

1. Sciarrone D, Ragonese C, Carnovale C, Piperno A, Dugo P, Dugo G, et al. Evaluation of tea tree oil quality and ascaridole: a deep study by means of chiral and multi heart-cuts multidimensional gas chromatography system coupled to mass spectrometry detection. J. Chromatogr. A. 2010 Oct 8; 1217(41):6422-7.

2. Wilson PG, O'Brien MM, Gadek PA, Quinn CJ. Myrtaceae revisited: a reassessment of infrafamilial groups. Am. J. Bot. 2001 Nov; 88(11):2013-25.

3. Craven LA, Lepschi BJ. Enumeration of the species and infraspecific taxa of Melaleuca (Myrtaceae) occurring in Australia and Tasmania. Aust. Syst. Bot. 1999 Dec; 12 (6):819-928.

4. Craven, L. A. Behind the names: the botany of tea tree, cajuput and niaouli,. In I. Southwell and R. Lowe (ed.), Tea tree: the genus Melaleuca. Netherlands. Harwood Academic Publishers; 1999. vol. 9: p. 11-28. 
5. Simpson SJ, Le Couteur DG, Raubenheimer D, Solon-Biet SM, Cooney GJ, Cogger VC, et al. Dietary protein, aging and nutritional geometry.Ageing Res. Rev. 2017 Oct 1; 39:78-86.

6. Reynertson KA, Yang H, Jiang B, Basile MJ, Kennelly EJ. Quantitative analysis of antiradical phenolic constituents from fourteen edible Myrtaceae fruits. Food chemistry. 2008 Aug 15; 109(4):883-90.

7. Farag RS, Shalaby AS, El-Baroty GA, Ibrahim NA, Ali MA, Hassan EM. Chemical and biological evaluation of the essential oils of different Melaleuca species. Phytother Res. 2004 Jan;18(1):30-5.

8. Aboutabl EA, Tohamy SE, De Footer HL, De Buyck LF. A comparative study of the essential oils from three Melaleuca species growing in Egypt. Flavour Fragr. J. 1991 Jun;6(2):139-41.

9. Brophy JJ, Goldsack RJ, Craven LA, O'Sullivan W. An investigation of the leaf oils of the western Australian broombush complex (Melaleuca uncinata Sens. Lat.)(Myrtaceae). J. Essent. Oil Res. 2006 Nov 1;18(6):5919.

10. Hnawia E, Brophy JJ, Craven LA, Lebouvier N, Cabalion P, Nour M. An examination of the leaf essential oils of the endemic Melaleuca (Myrtaceae) species of New Caledonia. J. Essent. Oil Res. 2012 Jun 1;24(3):2738.

11. Gupta N, Manika N, Singh S, Singh SC, Pragadheesh VS, Yadav A. et al. Investigation on phenylpropanoids rich Melaleuca decora (Salisb.) Britt. essential oil. Nat. Prod. Res. 2012 Oct 1;26(20):1945-7.

12. Silva CJ, Barbosa LC, Maltha CR, Pinheiro AL, Ismail FM. Comparative study of the essential oils of seven Melaleuca (Myrtaceae) species grown in Brazil. Flavour Fragr. J. 2007 Nov;22(6):474-8.

13. Silva CJ, Barbosa LC, Demuner AJ, Montanari RM, Pinheiro AL, Dias I. et al. Chemical composition and antibacterial activities from the essential oils of Myrtaceae species planted in Brazil. Química Nova. 2010;33:104-8.

14. Trilles BL, Bombarda I, Bouraïma-Madjebi S, Raharivelomanana P, Bianchini JP, Gaydou EM. Occurrence of various chemotypes in niaouli [Melaleuca quinquenervia (Cav.) ST Blake] essential oil from New Caledonia. Flavour Fragr. J.2006 Jul;21(4):677-82.

15. Wheeler GS, Pratt PD, Giblin-Davis RM, Ordung KM. Intraspecific variation of Melaleuca quinquenervia leaf oils in its naturalized range in Florida, the Caribbean, and Hawaii. Biochem. Syst. Ecol. 2007 Aug 1;35(8):489-500.

16. Brophy, J. J. Potentially commercial melaleucas in I. A. Southwell and R. F. Lowe (Eds.). Tea Tree, the Genus Melaleuca in R. Hardman (ed.). Medicinal and Aromatic Plants-Industrial Profiles. Amsterdam: Harwood Academic Publishers; 1999.pp 247-274.

17. Attman PM. Australian tea tree oil. AJP. 1988 Apr; 69(817):276-8.

18. Johns MR, Johns JE, Rudolph V. Steam distillation of tea tree (Melaleuca alternifolia) oil. J. Sci. Food Agric. 1992;58(1):49-53.

19. Bagg J, Jackson MS, Sweeney MP, Ramage G, Davies AN. Susceptibility to Melaleuca alternifolia (tea tree) oil of yeasts isolated from the mouths of patients with advanced cancer. J. Oral Oncol. 2006 May $1 ; 42(5): 487-92$.

20. Garozzo A, Timpanaro R, Stivala A, Bisignano G, Castro A. Activity of Melaleuca alternifolia (tea tree) oil on Influenza virus A/PR/8: Study on the mechanism of action. Antiviral Res. 2011 Jan 1;89(1):83-8.

21. Carson CF, Hammer KA, Riley TV. Melaleuca alternifolia (tea tree) oil: a review of antimicrobial and other medicinal properties. Clin Microbiol Rev. 2006 Jan;19(1):50-62.

22. Amri I, Mancini E, De Martino L, Marandino A, Lamia H, Mohsen H, et al. Chemical composition and biological activities of the essential oils from three Melaleuca species grown in Tunisia. Int. J. Mol. Sci. 2012 Dec;13(12):16580-91.

23. Adams RP. Identification of essential oil components by gas chromatography/mass spectrometry. $4^{\text {th }}$ edition: Carol Stream, IL: Allured publishing corporation; 2007.

24. Liu H, Qiu N, Ding H, Yao R. Polyphenols contents and antioxidant capacity of 68 Chinese herbals suitable for medical or food uses. Int. Food Res. J. 2008 Jan 1;41(4):363-70.

25. Lu M, Yuan B, Zeng M, Chen J. Antioxidant capacity and major phenolic compounds of spices commonly consumed in China. Int. Food Res. J. 2011 Mar 1;44(2):530-6.

26. Pal J, Singh SP, Prakash O, Batra M, Pant AK, Mathela CS. Hepatoprotective and antioxidant activity of Zingiber chrysanthum Rosec. rhizomes. Asian J. Tradit. Med. 2011 Dec 1;6(6).

27. Arya N, Prakash O, Verma AK, Pant AK. Variation in antioxidant potential of Curcuma longa L. collected from different ecological niches of Western Himalayan region. Int. J. Pharm. Pharm. 2015;7(7):85-90.

28. Naskar S, Mazumder UK. Antioxidant potential and hepatoprotectivity of hydromethanolic extract of Litchi chinensis fruits: In vivo and in vitro studies Iran. J. Pharmacol. Ther. 2016 Aug 10;14(2):1. 
29. Wie MB, Won MH, Lee KH, Shin JH, Lee JC, Suh HW, et al. Eugenol protects neuronal cells from excitotoxic and oxidative injury in primary cortical cultures. Neurosci. Lett. 1997 Apr 4;225(2):93-6.

30. Nene, Y.L and P.N. Thapliyal (Internet crop research institute for the semi-Arid Tropics). Fungicides in plant disease control. 1979. Vol. II.

31. Feng W, Zheng X. Essential oils to control Alternaria alternata in vitro and in vivo. Food control. 2007 Sep 1;18(9):1126-30.

32. Srivastava S, Singh RP. Antifungal activity of the essential oil of Murraya koenigii (L.) Spreng. Indian perfumer. 2001;45(1):49-52.

33. Donaldson JR, Warner SL, Cates RG, Gary Young D. Assessment of antimicrobial activity of fourteen essential oils when using dilution and diffusion methods. Pharm. Biol.2005 Jan 1;43(8):687-95.

34. Zaika LL. Spices and herbs: their antimicrobial activity and its determination. J. Food Saf. 1988 Jul;9(2):97118.

35. Chandra S, Chatterjee P, Dey P, Bhattacharya S. Evaluation of in vitro anti-inflammatory activity of coffee against the denaturation of protein. Asian Pac. J. Trop. Biomed. 2012 Jan 1;2(1): 178-180.

36. Padalia RC, Verma RS, Chauhan A, Goswami P, Verma SK, Darokar MP. Chemical composition of Melaleuca linarrifolia Sm. from India: a potential source of 1, 8-cineole. Ind Crops Prod. 2015a Jan; 63(1):264-268.

37. Goswami P, Verma SK, Chauhan A, Venkatesha KT, Verma RS, Singh VR, et al. Chemical composition and antibacterial activity of Melaleuca bracteata essential oil from India: A natural source of methyl eugenol. Nat. Prod. Commun. 2017 Jun;12(6): 965-968.

38. Kumar A, Tandon S, Yadav A. Chemical composition of the essential oil from fresh leaves of Melaleuca leucadendron L. from north India. J. Essent. Oil-Bear. Plants. 2005 Jan 1;8(1):19-22.

39. Pujiarti R, Ohtani Y, Ichiura H. Physicochemical properties and chemical compositions of Melaleuca leucadendron leaf oils taken from the plantations in Java, Indonesia. J. Wood Sci. 2011 Oct;57(5):446-51.

40. Siddique S, Parveen Z, Firdaus-e-Bareen, Mazhar S, Chaudhary MN, Saeed K. Chemical composition, antioxidant and antimicrobial activities of essential oil from Callistemon viminalis (Gaertn.) G. Don leaves. J. Essent. Oil-Bear. Plants. 2017 Mar 4;20(2):524-34.

41. Padalia RC, Verma RS, Chauhan A, Chanotiya CS. The essential oil composition of Melaleuca leucadendra L. grown in India: A novel source of (E)-nerolidol. Ind Crops Prod. 2015b Jul; 69(1):224-227.

42. Butcher PA, Bell JC, Moran GF. Patterns of genetic diversity and nature of the breeding system in Melaleuca alternifolia (Myrtaceae). Aust. J. Bot. 1992;40(3):365-75.

43. Park HM, Kim J, Chang KS, Kim BS, Yang YJ, Kim GH, et al. Larvicidal activity of Myrtaceae essential oils and their components against Aedes aegypti, acute toxicity on Daphnia magna, and aqueous residue. J. Med. Entomol. 2011 Mar 1;48(2):405-10.

44. Southwell IA, Stiff IA, Brophy JJ. Terpinolene varieties of Melaleuca. J. Essent. Oil Res. 1992 Jul 1;4(4):363-7.

45. Pino J, Bello A, Urquiola A, Aguero J, Marbot R. Chemical composition of cajuput oil (Melaleuca leucadendra L.) from Cuba. J. Essent. Oil Res. 2002 Jan 1;14(1):10-11.

46. Pino JA, Regalado EL, Rodríguez JL, Fernández MD. Phytochemical Analysis and in vitro Free-Radical-Scavenging Activities of the Essential Oils from Leaf and Fruit of Melaleuca leucadendra $\mathrm{L}$. Chem. Biodivers. 2010 Sep;7(9):2281-2288.

47. Ye ZM, Liu X, Shen MJ, Chen JY, Chen XD, Li YY. Optimization of process for extraction from Melaleuca bracteata essential oil with organic solvent and chemical composition identify. J. of Tropical Crop. Sci. 2014;35(5):992-998.

48. Almarie A, Mamata A, Rukunudina I. Chemical composition and herbicidal effects of Melaleuca bracteata F. Muell. essential oil against some weedy species. Int. J. Eng. Res.2016;7(1):507

49. Dorman HD, Deans SG. Antimicrobial agents from plants: antibacterial activity of plant volatile oils. J. Appl. Microbiol. 2000 Feb;88(2):308-16.

50. Rabe T, Van Staden J. Antibacterial activity of South African plants used for medicinal purposes. J. Ethnopharmacol. 1997 Mar 1;56(1):81-7.

51. Di Campli E, Di Bartolomeo S, Pizzi PD, Di Giulio M, Grande R, Nostro A, et al. Activity of tea tree oil and nerolidol alone or in combination against Pediculus capitis (head lice) and its eggs. Parasitol. Res. 2012 Nov;111(5):1985-92.

52. Klopell FC, Lemos M, Sousa JP, Comunello E, Maistro EL, Bastos JK, et al. Nerolidol, An antiulcer constituent from the essential oil of Baccharis dracunculifolia DC (Asteraceae). Z. Naturforsch. C. 2007 Aug 1;62(7-8):537-42. 
53. Lapczynski A, Bhatia SP, Letizia CS, Api AM. Fragrance material review on nerolidol (isomer unspecified). Food Chem. Toxicol. 2008 Nov 1;46(11): 247-250.

54. Krist S, Banovac D, Tabanca N, Wedge DE, Gochev VK, Wanner J, et al. Antimicrobial activity of nerolidol and its derivatives against airborne microbes and further biological activities. Nat. Prod. Commun. 2015 Jan;10(1):143-148.

55. ISHII HT, SUNARTO S, KANAZAWA Y. Variation in Kayu Putih (Melaleuca leucadendron Linn) oil quality under different farming systems in Java, Indonesia. Eur. J. For. Res. 2005 Feb;8(1):15-20.

56. Juergens UR, Dethlefsen U, Steinkamp G, Gillissen A, Repges R, Vetter H. Anti-inflammatory activity of 1.8cineol (eucalyptol) in bronchial asthma: a double-blind placebo-controlled trial. Respir. Med. 2003 Mar 1;97(3):250-256.

57. Ebadollahi, A. Essential oils isolated from myrtaceae family as natural insecticides. Annu. Rev. Res. Biol. 2013 April; 148-175.

58. Barbosa LC, Silva CJ, Teixeira RR, Meira RM, Pinheiro AL. Chemistry and biological activities of essential oils from Melaleuca L. species. Agric. Conspec. Sci. 2013 Mar 27;78(1):11-23.

59. Choi YK, Cho GS, Hwang S, Kim BW, Lim JH, Lee JC, et al. Methyleugenol reduces cerebral ischemic injury by suppression of oxidative injury and inflammation. Free Radic. Res. 2010 Aug 1;44(8):925-35.

60. Müller M, Pape HC, Speckmann EJ, Gorji A. Effect of eugenol on spreading depression and epileptiform discharges in rat neocortical and hippocampal tissues. Neuroscience. 2006 Jan 1;140(2):743-51.

61. Suresh B, Sriram S, Dhanaraj SA, Elango K, Chinnaswamy K. Anticandidal activity of Santolina chamaecyparissus volatile oil. J. Ethnopharmacol. 1997 Jan 1;55(2):151-9.

62. Ali SM, Khan AA, Ahmed I, Musaddiq M, Ahmed KS, Polasa H, et al. Antimicrobial activities of Eugenol and Cinnamaldehyde against the human gastric pathogen Helicobacter pylori. Ann Clin Microbiol Antimicrob. 2005 Dec;4(1):1-7.

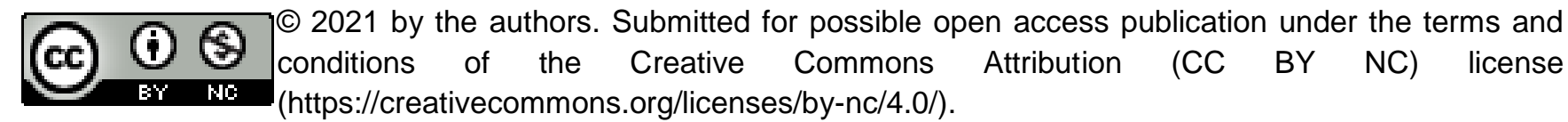

